Research Article

\title{
Binary Political Optimizer for Feature Selection Using Gene Expression Data
}

\author{
Ghaith Manita $\mathbb{D}^{1,2}$ and Ouajdi Korbaa $\mathbb{D}^{1}$ \\ ${ }^{1}$ Laboratory MARS, LR17ES05, ISITCom, University of Sousse, Sousse, Tunisia \\ ${ }^{2}$ ESEN, University of Manouba, Manouba, Tunisia \\ Correspondence should be addressed to Ghaith Manita; gaieth.manita@gmail.com
}

Received 9 September 2020; Revised 2 November 2020; Accepted 16 November 2020; Published 29 November 2020

Academic Editor: Wassim Ayadi

Copyright (c) 2020 Ghaith Manita and Ouajdi Korbaa. This is an open access article distributed under the Creative Commons Attribution License, which permits unrestricted use, distribution, and reproduction in any medium, provided the original work is properly cited.

\begin{abstract}
DNA Microarray technology is an emergent field, which offers the possibility of obtaining simultaneous estimates of the expression levels of several thousand genes in an organism in a single experiment. One of the most significant challenges in this research field is to select high relevant genes from gene expression data. To address this problem, feature selection is a well-known technique to eliminate unnecessary genes in order to ensure accurate classification results. This paper proposes a binary version of Political Optimizer (PO) to solve feature selection problem using gene expression data. Two transfer functions are used to design a binary PO. The first one is based on Sigmoid function and will be noted as BPO-S, while the second one is based on V-shaped function and will be noted as BPO-V. The proposed methods are evaluated using 9 biological datasets and compared with 8 binary well-known metaheuristics. The comparative results show the prevalent performance of the BPO methods especially BPO-V in comparison with other techniques.
\end{abstract}

\section{Introduction}

Molecular biology research evolves through the development of technologies used to carry them out. It is not possible to investigate a countless number of genes using conventional strategies. DNA Microarray is a technology that allows researchers to investigate and treat problems that were once considered untraceable. The expression of many genes can be examined in a solitary response rapidly and productively. DNA Microarray technology is enabling the scientific community to understand the fundamental aspects underlying the growth and development of life, as well as to investigate the hereditary reasons for irregularities in the working of the human body.

Therefore, microarray technology remains to this day a useful asset for measuring of gene expression. Beyond the technology itself, the analysis of the data from microarrays is a complex statistical problem. And this is due to the large number of genes and the complexity of biological networks which increase the challenges of understanding and interpreting the resulting mass of data, which often consists of millions of measurements. Hence, extracting relevant biological knowledge from microarray data turns into a hard task due to the curse of dimensionality problem [1].

Generally, gene expression data are often redundant and noisy with large number of genes. In order to reduce the dimensionality of such datasets by selecting the most informative features, Feature Selection (FS) procedure seems to be an essential preprocessing phase before the implementation of machine learning classifiers in order to minimize training times and memory requirements [2].

Feature selection methods are classified into three categories based on the evaluation criteria used: filter, wrapper, and embedded [3]. This categorization depends on the involvement of a learning algorithm in the used approach.

The filter methods (Chi-Square [4], Information Gain [5], Gain Ratio [6], and ReliefF [7]) select a subset of variables by preprocessing the data from a model. The selection process is independent of the classification process. One of the advantages is that it is completely independent of the 
data model we are trying to build. It proposes a satisfactory subset of variables to explain the structure of the hidden data and that the subset is independent of the chosen learning algorithm. On the contrary, wrapper methods aim to generate representative subsets and evaluate them using a classification algorithm. This evaluation is carried out by calculating a score, e.g., a score of a set will be a compromise between the number of variables eliminated and the success rate of the classification on a test set. Therefore, wrapper methods are more exact than the filter approaches since they consider the relations among the features. Another advantage is its conceptual simplicity; we do not need to understand how induction is affected by the selection of variables, just generate and test. Nevertheless, the computational cost is significantly increased and depends on the used learning algorithm [8]. Finally, embedded methods integrate selection directly into the learning process, and decision trees are the most emblematic illustration. However, we classify in this group all techniques that evaluate the importance of a variable in coherence with the criterion used to evaluate the overall relevance of the model. They are generally known by their reasonable trade-off between efficiency and computing costs $[9,10]$.

FS is regarded as an NP-complete combinatorial optimization problem [11]. The search space size is strongly dependent to the increase of the number of features in the studied dataset. An exhaustive search for the optimal relevant feature often leads to stagnation in local optima [12]. Therefore, metaheuristic methods are potentially more suitable to deal with this problem because of their ability to find acceptable solutions in reasonable periods of time [13]. The objective function may be the accuracy of the classification or another criterion that could consider the best compromise between the computational burden of attribute extraction and efficiency [14]. Metaheuristics are stochastic approaches and fall into two categories: population-based approaches and single-solution approaches $[14,15]$. Generally, they are inspired by nature, social behavior, biological behavior of animals or birds or insects, physical or chemical phenomena, etc.

In the literature, many works were introduced in order to implement stochastic methods to address the FS problem, such as Simulated Annealing (SA) [16], Tabu Search (TS) [17, 18], Genetic Algorithm (GA) [19-22], Particle Swarm Optimization (PSO) [23, 24], Ant Colony Optimization (ACO) [25, 26], Artificial Bee Colony (ABC) [27, 28], and Differential Evolution (DE) [29, 30].

Generally, these traditional methods suffer from a slow convergence rate, and they have a lot number of parameters to be tuned. Hence, a simple and efficient global search technique is needed. For that, during this work, we use the Policy Optimizer (PO) [31] as the main resolution technique since it is a newly introduced metaheuristic which is human behavior-based algorithm. Moreover, as mentioned in [31], PO produces better solutions for dealing with optimization problems than other well-known metaheuristics in the literature. In this paper, a novel binary version is proposed to find the most representative subset of a given dataset. The binary version introduced here is performed using two different transfer functions.
The structure of this paper is as follows: the standard (continuous) version of Political Optimizer (PO) is presented in Section 2. In Section 3, we introduce the binary version of the latter algorithm called BPO. The obtained results and conducted comparisons are reported in Section 4. Finally, the conclusion and several directions for future papers are stated in Section 5.

\section{Overview of the Political Optimizer (PO)}

Political Optimizer is a newly proposed metaheuristic based on human behavior and inspired by the multiphased political process. However, it should be noted that the proposed algorithm is not the first of this kind. In PO, the concept of politics is mapped from a different perspective and unlike the recent politics-inspired algorithms, and this is due to four reasons. First, PO tries to model all the important steps in politics such as party formation, party-ticket/constituency allocation, election campaign and party switching, interparty election, and parliamentary affairs after government formation. Second, PO introduces a novel position updating strategy called recent past-based position updating strategy (RPPUS). This latter represents the learning behavior of politicians from the previous election. Third, each individual solution assumes a double job: a party member and an election candidate. Using this concept, each solution can be updated according to two better solutions: the party leader and the constituency winner. Finally, to improve the results, intermediary solutions needs to cooperate and communicate via a phase named parliamentary affairs.

In $\mathrm{PO}$, each party member is viewed as a candidate solution where its goodwill is considered the position in the search space. Moreover, the evaluation function is computed during the election phase where the number of votes obtained by each member party represents the fitness of the candidate solution.

Political Optimizer (PO) is formed by five main phases as follows: party formation and constituency allocation, election campaign, party switching, interparty election, and parliamentary affairs. It should be mentioned that the first phase (party formation and constituency allocation) is executed only one time to initialize and affect different variables. However, the remaining phases are running in loop, as detailed in Algorithm 1. The used variables in PO are summarized in Table 1.

2.1. Party Formation and Constituency Allocation. In the beginning, the population $P$ is partitioned in $N$ parties, where each party $P_{i}$ includes $N$ members (potential solution). Moreover, each $j$ th member is noted as $P_{i}^{j}$ and represented by a $d$-dimensional vector, where the value $d$ is the number of input variables of the treated problem and $P_{i, k}^{j}$ is $k$ th dimension of $P_{i}^{j}$.

As mentioned before, each member is considered as an election candidate besides its role as a party member. Hence, $N$ constituencies are formed and contain $j$ th member of each contesting party. This division is illustrated in Figure 1. Furthermore, the leader of the $i$ th party after computing the 


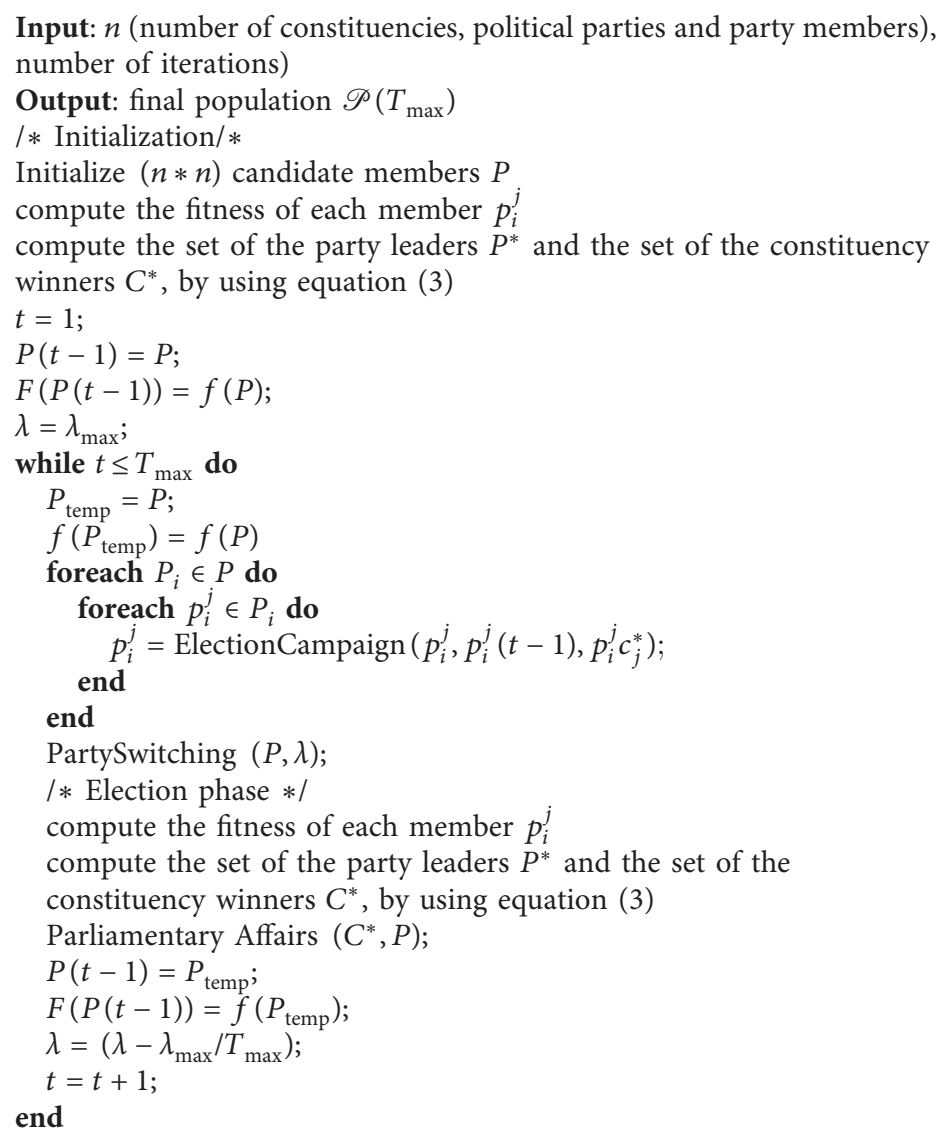

Algorithm 1: Pseudocode of PO.

TABLE 1: List of the used variables.

\begin{tabular}{lc}
\hline Variable & Description \\
\hline$P$ & Set of all political parties (whole population) \\
$P_{i}$ & ith political party \\
$P_{i}^{j}$ & $j$ th member of $i$ th party \\
$P_{i, k}^{j}$ & $k$ th dimension of $j$ th member of $i$ th political party \\
$C$ & Set of all constituencies \\
$C_{j}$ & $j$ th constituency \\
$P_{i}^{*}$ & Leader of $i$ th political party \\
$C_{j}^{*}$ & Winner of $j$ th constituency \\
$\lambda$ & Party switching rate \\
$N$ & Number of parties, constituencies, and members in each \\
$T_{\max }$ & Total number of iterations \\
\hline
\end{tabular}

fitness of all member is noted as $P_{i}^{*}$ and the set of all the party leaders is represented by $P^{*}$. On the contrary, after the election, $C^{*}$ regroups the winners from all the constituencies named the parliamentarians, where $C_{j}^{*}$ denotes the winner of $j$ th constituency.

2.2. Election Campaign. During this phase, party members are trying to enhance their chances of being elected by changing their positions according to three aspects. First, they try to learn from previous experience using a novel

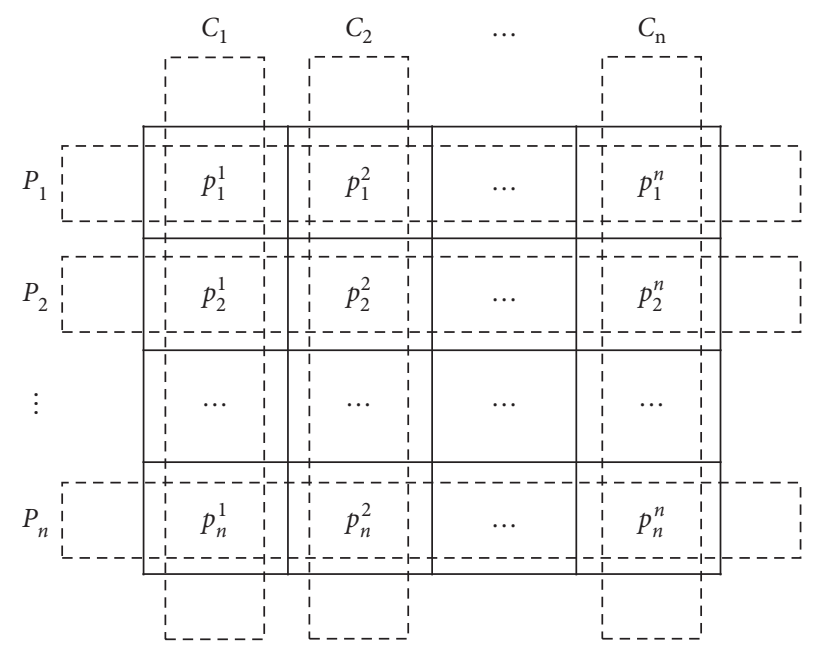

FIgURE 1: Illustration of the logical division of the population $P$ in political parties and constituencies [31].

position updating strategy called recent past-based position updating strategy (RPPUS), as formulated in equations (1) and (2). Second, each party member is trying to update his current position according to the party leader. Finally, candidate positions are updated with reference to the constituency winner: 


$$
\begin{aligned}
& P_{i, k}^{j}(t+1)= \begin{cases}m^{*}+r\left(m^{*}-P_{i, k}^{j}(t)\right), & \text { if } P_{i, k}^{j}(t-1) \leq P_{i, k}^{j}(t) \leq m^{*} \text { or } P_{i, k}^{j}(t-1) \geq P_{i, k}^{j}(t) \geq m^{*}, \\
m^{*}+(2 r-1)\left|m^{*}-P_{i, k}^{j}(t)\right|, & \text { if } P_{i, k}^{j}(t-1) \leq m^{*} \leq P_{i, k}^{j}(t) \text { or } P_{i, k}^{j}(t-1) \geq m^{*} \geq P_{i, k}^{j}(t), \\
m^{*}+(2 r-1)\left|m^{*}-P_{i, k}^{j}(t-1)\right|, & \text { if } m^{*} \leq P_{i, k}^{j}(t-1) \leq P_{i, k}^{j}(t) \text { or } m^{*} \geq P_{i, k}^{j}(t-1) \geq P_{i, k}^{j}(t),\end{cases} \\
& P_{i, k}^{j}(t+1)= \begin{cases}m^{*}+(2 r-1)\left|m^{*}-P_{i, k}^{j}(t)\right|, & \text { if } P_{i, k}^{j}(t-1) \leq P_{i, k}^{j}(t) \leq m^{*} \text { or } P_{i, k}^{j}(t-1) \geq P_{i, k}^{j}(t) \geq m^{*}, \\
P_{i, k}^{j}(t-1)+r\left(P_{i, k}^{j}(t)-P_{i, k}^{j}(t-1)\right), & \text { if } P_{i, k}^{j}(t-1) \leq m^{*} \leq P_{i, k}^{j}(t) \text { or } P_{i, k}^{j}(t-1) \geq m^{*} \geq P_{i, k}^{j}(t), \\
m^{*}+(2 r-1)\left|m^{*}-P_{i, k}^{j}(t-1)\right|, & \text { if } m^{*} \leq P_{i, k}^{j}(t-1) \leq P_{i, k}^{j}(t) \text { or } m^{*} \geq P_{i, k}^{j}(t-1) \geq P_{i, k}^{j}(t) .\end{cases}
\end{aligned}
$$

According to Algorithm 2, which describes the whole process of election campaign, the relationship between current fitness and the previous fitness is the main factor to choose between using equations (1) or (2).

2.3. Party Switching. In order to balance between exploration and exploitation, a phase called party switching is started after the election campaign phase. Using an adaptive parameter $\lambda$ named party switching rate, each party member $P_{i}^{j}$ can be selected and switched to some randomly chosen party $P_{r}$. Hence, it is swapped with the least fit member of the party $P_{r}$, as presented in Algorithm 3.

2.4. Election. This phase aims to evaluate the fitness of all candidates contesting in constituency. After that, the party leaders and constituency winners are updated as follows:

$$
\begin{aligned}
q & =\arg \min f\left(P_{i}^{j}\right), \quad 1 \leq i \leq N, \\
C_{j}^{*} & =P_{q}^{i}, \\
P_{j}^{*} & =P_{q}^{i} .
\end{aligned}
$$

2.5. Parliamentary Affairs. After determining the party leaders and constituency winners (parliamentarians), each parliamentarian aims to improve his performance in order to mimic the interaction and cooperation of the winning candidates to run the government in the postelection phase. This process is presented in Algorithm 4, where each parliamentarian $C_{j}^{*}$ updates its position in relation to randomly chosen parliamentarian $C_{r}^{*}$. It should be noted that the movement is applied only if the performance of $C_{j}^{*}$ is enhanced.

\section{Binary Political Optimizer (BOP)}

As mentioned before, political member's goodwill is considered as a candidate position and moves in the search space towards continuous-valued positions. However, in binary optimization problems, such as feature selection, the search space is modelled as a $n$-dimensional Boolean lattice, and political member's goodwill needs to be represented by binary vectors.

In order to convert a continuous algorithm to a binary version, we should utilize transfer functions (TF), and it considered as the most efficient and convenient way [32]. Transfer functions are classified into two categories according to their shapes: S-shaped and V-shaped, as illustrated in Figure 2.

In this work, two versions are proposed, based on the transfer function used. In the first one, the political member's goodwill is updated using the Sigmoid function (Sshaped) and called BPO-S. While, in the second one, we used the Hyperbolic Tangent transfer function, called BPO-V.

Without any modification in the previously detailed phases, only two steps are integrated after the continuous computation. The first step is to calculate the probability of changing a position's element to 0 or 1 according to the following equation:

$$
P\left(x_{d}^{i}(t)\right)=\operatorname{TF}\left(x_{d}^{i}(t)\right),
$$

where TF is the used transfer function that could be Sigmoid (equation (5)) or Hyperbolic Tangent (equation (6)) and $x_{d}^{i}(t)$ is the $i$ th political member in the $d$ th in the iteration $t$ :

$$
\begin{gathered}
\operatorname{TF}(x)=\frac{1}{1+e^{-x}}, \\
\operatorname{TF}(x)=|\tanh (x)| .
\end{gathered}
$$

In the second step, the probability computed by equation (4) is then inserted in equation (7) in order to convert continuous value of each member position to 0 or 1 :

$$
x_{d}^{i}(t)= \begin{cases}1, & \text { if } P\left(x_{d}^{i}(t)\right) \geq \text { rand } \\ 0, & \text { otherwise, }\end{cases}
$$

where rand is a uniform random number between 0 and 1 .

The flowchart of the proposed binary algorithm is presented in Figure 3.

3.1. Binary Political Optimizer Applied for Feature Selection. In this section, we exploited the proposed BPO in feature selection for classification problems. As mentioned before, the feature selection problem is an NP-hard combinatorial binary optimization problem. For a feature vector sized $N$, the different feature combinations would be $2 \mathrm{~N}$ which increase exponentially the number of possible solutions where an exhaustive search is probably not practical. Therefore, we used the proposed BPO in order to find an acceptable solution with reasonable execution time. The main objective is to maximize the classification accuracy and minimize the 


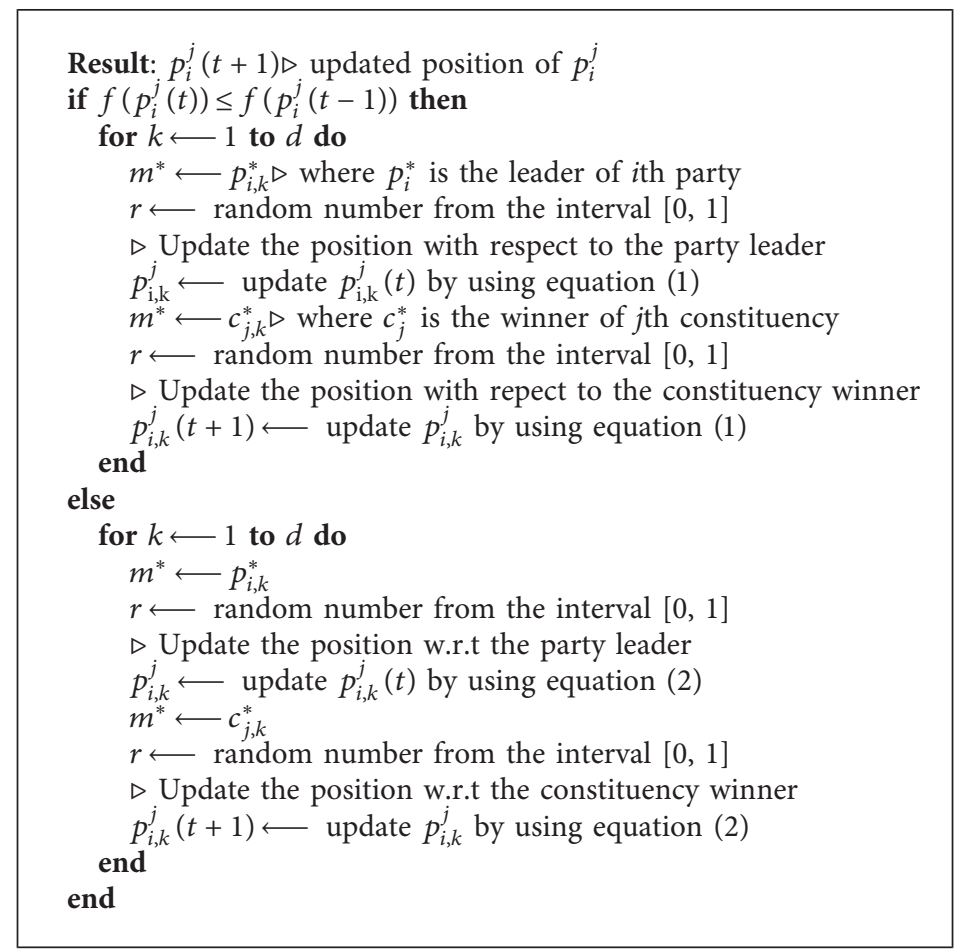

Algorithm 2: ElectionCampaign $\left(p_{i}^{j}, p_{i}^{j}(t-1), p_{i}^{j}, c_{j}^{*}\right)$.

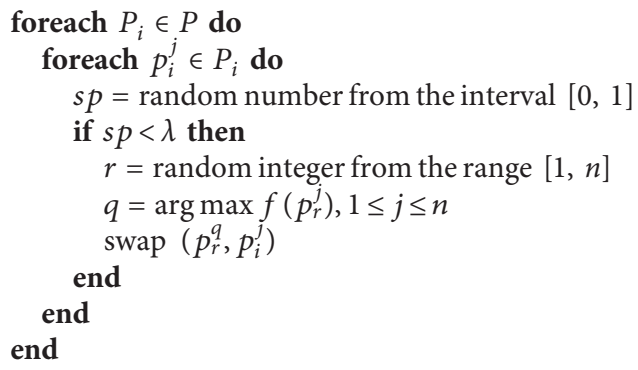

Algorithm 3: PartySwitching $(P, \lambda)$.

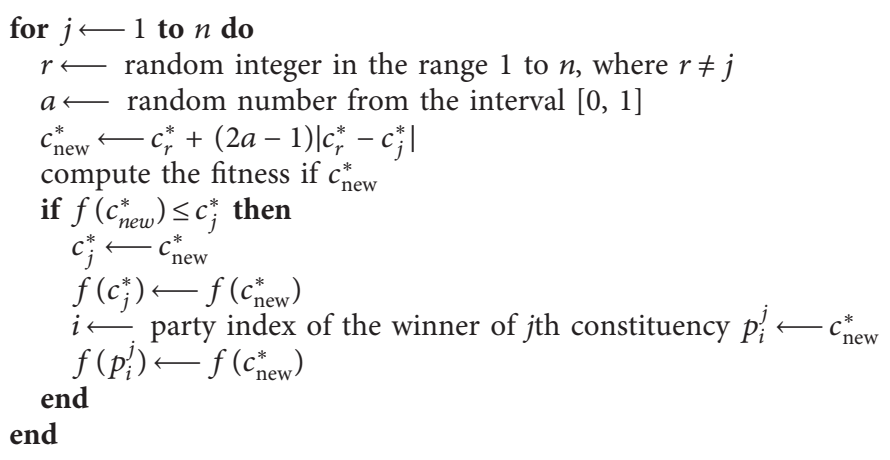

Algorithm 4: PartySwitching (parliamentary affairs $\left.\left(C^{*}, P\right)\right)$. 


$$
\begin{aligned}
& S 1 \quad T(x)=\frac{1}{1+e^{-2 x}} \quad \text { S3 } \quad T(x)=\frac{1}{1+e^{-x / 2}} \\
& S 2 \quad T(x)=\frac{1}{1+e^{-x}} \quad S 4 \quad T(x)=\frac{1}{1+e^{-x / 3}}
\end{aligned}
$$

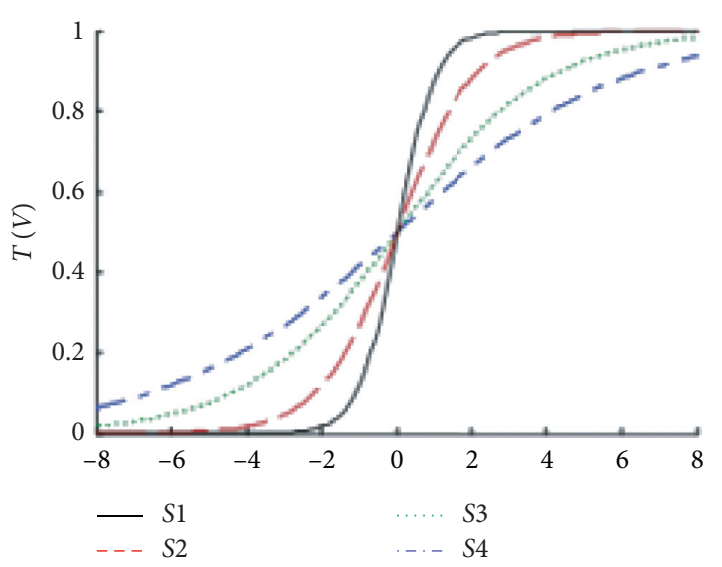

(a)

$$
\begin{aligned}
& \text { V1 } T(x)=\left|\operatorname{erf}\left(\frac{\sqrt{\pi}}{2} x\right)\right| \quad \text { V3 } T(x)=\left|\frac{x}{\sqrt{1+x^{2}}}\right| \\
& \text { V2 } T(x)=|\tanh (x)| \quad \text { V4 } T(x)=\left|\frac{2}{\pi} \arctan \left(\frac{\pi}{2} x\right)\right|
\end{aligned}
$$

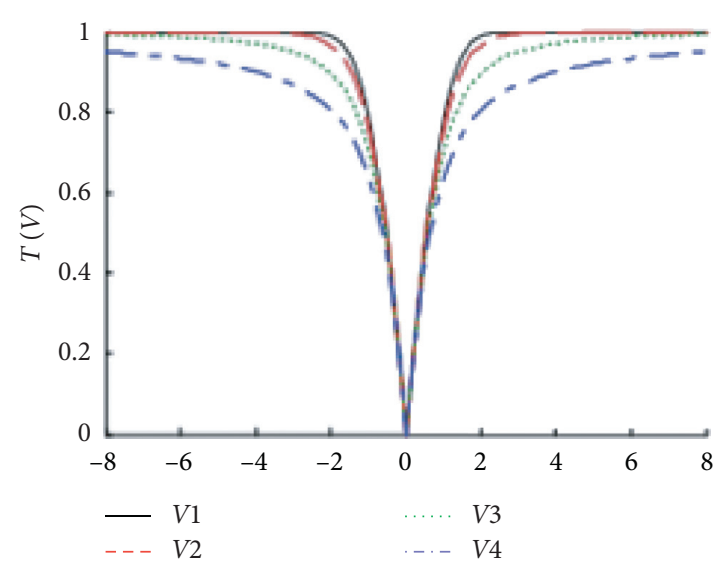

(b)

Figure 2: (a) S-shaped and (b) V-shaped family of transfer functions [32].

number of selected features. The used fitness function is presented in the following equation [33]:

$$
\uparrow F=\mathrm{Acc}+\omega\left(1-\frac{s f}{n f}\right),
$$

where Acc is the classification accuracy given a chosen classifier, $\omega$ is the weight factor which is a value between 0 and $1, s f$ is the length of selected feature subset, and $n f$ is the total number of features. In this study, we set $\omega$ to 0.5 for all the experiments in the next section. For the classifier, we chose to use $k$-Nearest Neighbor $(k-\mathrm{NN})$ to compute the accuracy of selected subset. Moreover, to ensure the robustness of the obtained results, every used dataset is divided randomly into two different parts: training and testing set, according to 10 -fold crossvalidation method.

\section{Experimental Results}

In this section, all experiments were repeated for 100 independent times to obtain statistically meaningful results. Furthermore, each algorithm was implemented using MATLAB R2020a and was run on an Intel Core i7 machine, 2.6 GHz CPU, and $16 \mathrm{~GB}$ of RAM.

4.1. Dataset. In this study, nine benchmark biological datasets are used to assess the performance of the proposed approach [34-44]. Table 2 outlines the datasets used in this work.

4.2. Parameter Settings. To evaluate the proposed model, several experiments were conducted to compare the BPO algorithm with seven different metaheuristic optimization algorithms: Binary Particle Swarm Optimization (BPSO) [45], Binary Genetic Algorithm (BGA) [46], Binary Bat
Algorithm (BBA) [47], Binary Differential Evolution (BDE) [48], Binary Grey Wolf Optimizer (BGWO) [49], Binary Atom Search Algorithm (BASO) [50], Binary Harris Hawks Optimizer (BHHO) [51], and Binary Tree Growth Algorithm (BTGA) [52]. The parameters settings for all metaheuristic optimization algorithms are shown in Table 3.

4.3. Results and Discussion. In this section, we start to evaluate statically the performance of the two proposed version of BPO compared to other algorithms. Therefore, four different statistical measures are used to start the first step of evaluation. These measurements were the worst fitness value, the best fitness value, the mean fitness value (avg), and standard deviation (std). Table 4 outlines the obtained results using these measures where the best ones are highlighted in bold text. From the table, we assess the superiority of proposed algorithms, especially BPO-V, compared to others binary version of well-known algorithms. However, BPO-V and BPO-S can be described as unstable methods in most cases. This fact can be explained by the complexity of position update strategy adopted by PO. Furthermore, it can be observed that BASO is the most competitive algorithm with the two version of BPO. From these findings, it can be concluded that BPO-V is better than BPO-S, BGA, BGWO, BBA, BHHO, BDE, BASO, BPSO, and BTGA in extracting the most relevant feature of the tested datasets with the aim to maximize the classification performance and minimization of the number of selected features. This deduction was confirmed by applying a Wilcoxon Ranked Signed Test to the proposed algorithms compared in pairs with the other algorithms. This test is performed with a statistical significance value $\alpha=0.05$. In Tables 5 and 6 , the sign " + " in the winner lines designates that the null hypothesis is rejected and the proposed 


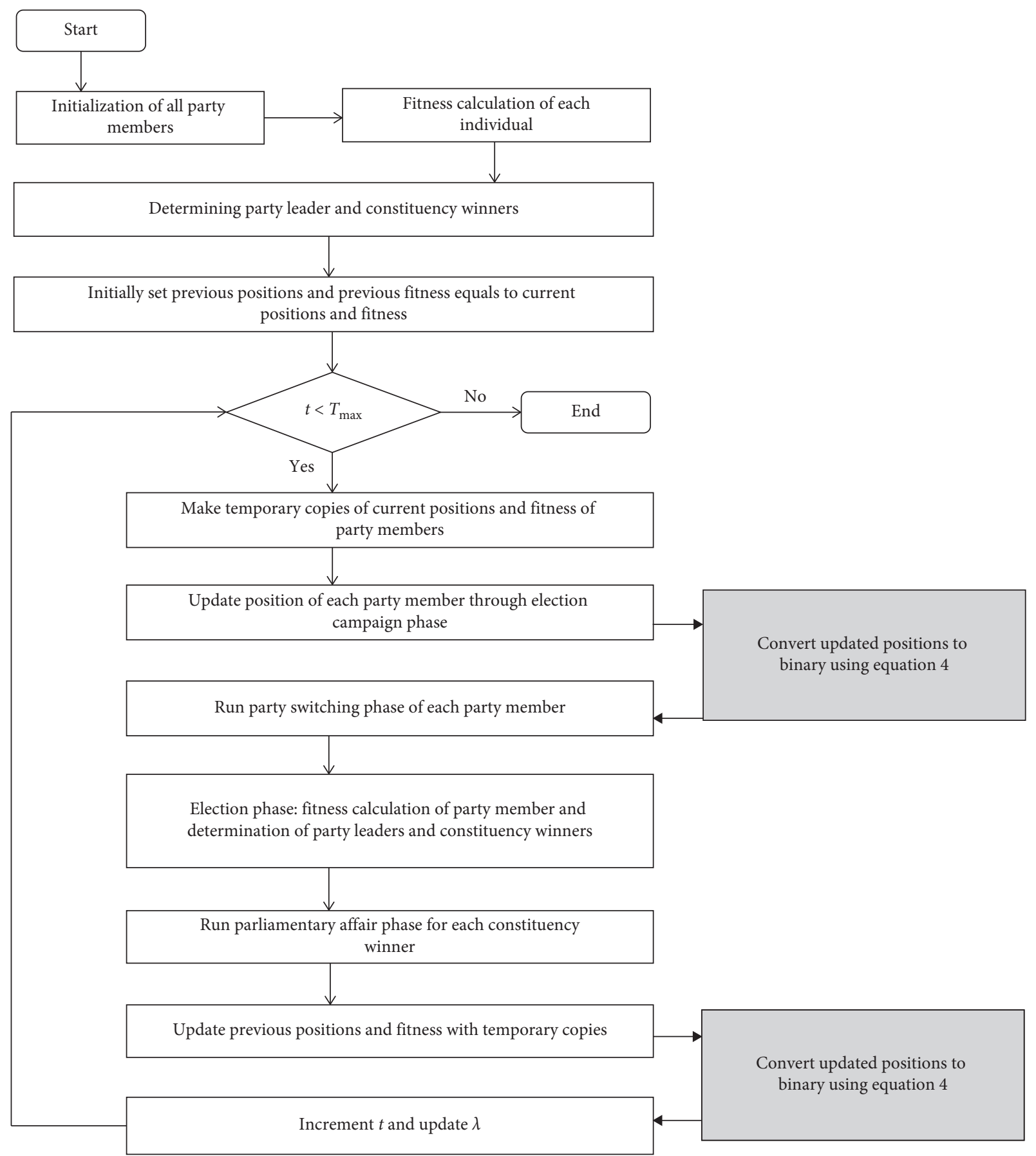

FIGURE 3: Flowchart of the proposed algorithm.

TABLE 2: Details of datasets.

\begin{tabular}{|c|c|c|c|c|}
\hline Dataset & No. of instances & No. of features & No. of classes & Type \\
\hline 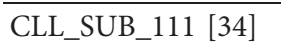 & 111 & 11340 & 3 & Continuous, multiclass \\
\hline Colon [35] & 62 & 2000 & 2 & Discrete, binary \\
\hline Leukemia [36] & 72 & 7070 & 2 & Discrete, binary \\
\hline Lung [37] & 203 & 3312 & 5 & Continuous, multiclass \\
\hline Lung_discrete [38] & 73 & 325 & 7 & Discrete, multiclass \\
\hline Lymphoma [39] & 96 & 4026 & 9 & Discrete, multiclass \\
\hline nci9 $[40,41]$ & 60 & 9712 & 9 & Discrete, multiclass \\
\hline Prostate_GE $[42,43]$ & 102 & 5966 & 2 & Continuous, binary \\
\hline SMK_CAN_187 [44] & 187 & 19993 & 2 & Continuous, binary \\
\hline
\end{tabular}


TABle 3: Parameter settings for all used algorithms.

\begin{tabular}{|c|c|c|}
\hline Algorithm & Parameter & Value \\
\hline BPO & $\begin{array}{l}\text { Parties (number of political parties) } \\
\text { Lambda (max limit of party switching rate) }\end{array}$ & $\begin{array}{l}5 \\
1 \\
\end{array}$ \\
\hline BPSO & $\begin{array}{c}\mathrm{c1} \text { (cognitive factor) } \\
\mathrm{c} 2 \text { (social factor) } \\
\text { Vmax (maximum velocity) } \\
\text { Wmax (maximum bound on inertia weight) } \\
\text { Wmin (minimum bound on inertia weight) }\end{array}$ & $\begin{array}{c}2 \\
2 \\
6 \\
0.9 \\
0.4\end{array}$ \\
\hline BGWO & $\mathrm{a}$ & 2 \\
\hline BBA & $\begin{array}{c}\text { Goma } \\
\text { Alpha } \\
\text { Zigma } \\
\text { Beta } \\
\text { frequencyMin } \\
\text { frequencyMax }\end{array}$ & \begin{tabular}{c|}
1 \\
1 \\
1 \\
1 \\
20 \\
50 \\
\end{tabular} \\
\hline $\mathrm{BDE}$ & CrossRate & 0.9 \\
\hline BTGA & $\begin{array}{l}\text { N1 (number of trees in first group) } \\
\text { N2 (number of trees in second group) } \\
\text { N4 (number of trees in fourth group) } \\
\text { Tree reduction rate } \\
\text { Parameter controls nearest tree }\end{array}$ & $\begin{array}{c}3 \\
5 \\
3 \\
0.8 \\
0.5 \\
\end{array}$ \\
\hline BHHO & Beta (levywalk) & 1.5 \\
\hline BASO & $\begin{array}{c}\text { Alpha (depth weight) } \\
\text { Beta (multiplier weight) } \\
\text { Vmax (maximum velocity) }\end{array}$ & $\begin{array}{c}50 \\
0.2 \\
6 \\
\end{array}$ \\
\hline BGA & $\begin{array}{l}\text { crossoverRate } \\
\text { mutationRate }\end{array}$ & $\begin{array}{l}0.9 \\
0.1\end{array}$ \\
\hline All of them & $\begin{array}{c}\text { SearchAgent(Bats, wolfs, particles, ....) } \\
\text { Maximum iterations }\end{array}$ & $\begin{array}{c}30 \\
100\end{array}$ \\
\hline
\end{tabular}

TABLE 4: Experimental result of the fitness function of the proposed algorithms compared to eight metaheuristics.

\begin{tabular}{|c|c|c|c|c|c|c|c|c|c|c|c|}
\hline Dataset & & BPO-S & BPO-V & BGA & BGWO & BBA & $\mathrm{BHHO}$ & BASO & $\mathrm{BDE}$ & BPSO & BTGA \\
\hline \multirow{4}{*}{ CLL_SUB_111 } & Best & 1.409 & 1.4217 & 1.2065 & 1.1769 & 1.2059 & 1.2547 & 1.4237 & 1.1254 & 1.2053 & 1.208 \\
\hline & Avg & 1.2509 & 1.3254 & 1.1287 & 1.0926 & 1.1239 & 1.1433 & 1.2922 & 1.0498 & 1.1254 & 1.119 \\
\hline & Worst & 1.0681 & 1.2528 & 1.0707 & 1.0368 & 1.0701 & 1.0894 & 1.2164 & 0.9753 & 1.0684 & 1.0685 \\
\hline & std & 0.0698 & 0.0347 & 0.0262 & 0.0288 & 0.0264 & 0.0317 & 0.037 & 0.0268 & 0.0282 & 0.0296 \\
\hline \multirow{4}{*}{ Colon } & Best & 1.4995 & 1.4998 & 1.284 & 1.2632 & 1.2715 & 1.3807 & 1.4888 & 1.2637 & 1.275 & 1.2712 \\
\hline & Avg & 1.4302 & 1.4922 & 1.2732 & 1.2551 & 1.2639 & 1.3433 & 1.4888 & 1.242 & 1.269 & 1.2633 \\
\hline & Worst & 1.3308 & 1.433 & 1.2637 & 1.237 & 1.257 & 1.3093 & 1.45 & 1.2043 & 1.2635 & 1.258 \\
\hline & std & 0.0527 & 0.0163 & 0.0036 & 0.0052 & 0.0026 & 0.0165 & 0.0086 & 0.0144 & 0.0025 & 0.0024 \\
\hline \multirow{4}{*}{ Leukemia } & Best & 1.4999 & 1.4999 & 1.276 & 1.2612 & 1.2627 & 1.3848 & 1.4914 & 1.2576 & 1.267 & 1.2637 \\
\hline & Avg & 1.458 & 1.497 & 1.2708 & 1.2546 & 1.2593 & 1.3613 & 1.476 & 1.2526 & 1.2626 & 1.2595 \\
\hline & Worst & 1.2772 & 1.4792 & 1.2649 & 1.2494 & 1.2567 & 1.3397 & 1.4628 & 1.2477 & 1.2597 & 1.2566 \\
\hline & std & 0.0433 & 0.0039 & 0.002 & 0.0022 & 0.0012 & 0.0102 & 0.0064 & 0.0023 & 0.0012 & 0.0015 \\
\hline \multirow{4}{*}{ Lung } & Best & 1.4967 & 1.4953 & 1.2876 & 1.2634 & 1.2674 & 1.3818 & 1.4857 & 1.2655 & 1.2736 & 1.2714 \\
\hline & Avg & 1.4491 & 1.4758 & 1.2791 & 1.2561 & 1.2631 & 1.361 & 1.471 & 1.254 & 1.2685 & 1.2635 \\
\hline & Worst & 1.394 & 1.4502 & 1.2716 & 1.2462 & 1.2597 & 1.341 & 1.4576 & 1.2446 & 1.2654 & 1.2601 \\
\hline & std & 0.0228 & 0.0101 & 0.003 & 0.0034 & 0.0016 & 0.0091 & 0.0064 & 0.0036 & 0.0019 & 0.002 \\
\hline \multirow{4}{*}{ Lung_discrete } & Best & 1.4892 & 1.4938 & 1.3292 & 1.2954 & 1.3062 & 1.3815 & 1.48 & 1.2862 & 1.3231 & 1.3062 \\
\hline & Avg & 1.3954 & 1.4257 & 1.3127 & 1.2693 & 1.2866 & 1.354 & 1.4611 & 1.2563 & 1.3012 & 1.2881 \\
\hline & Worst & 1.2631 & 1.3409 & 1.2954 & 1.2308 & 1.2754 & 1.32 & 1.4292 & 1.2108 & 1.2877 & 1.2754 \\
\hline & std & 0.0562 & 0.0281 & 0.0072 & 0.0136 & 0.0063 & 0.0124 & 0.0096 & 0.0137 & 0.0067 & 0.0064 \\
\hline \multirow{4}{*}{ Lymphoma } & Best & 1.422 & 1.4389 & 1.2083 & 1.161 & 1.1616 & 1.2821 & 1.4268 & 1.1574 & 1.1696 & 1.1644 \\
\hline & Avg & 1.3632 & 1.388 & 1.1992 & 1.1549 & 1.1583 & 1.2678 & 1.3785 & 1.1514 & 1.1656 & 1.1599 \\
\hline & Worst & 1.1578 & 1.3489 & 1.1909 & 1.1501 & 1.1563 & 1.2532 & 1.3636 & 1.1465 & 1.1624 & 1.1567 \\
\hline & std & 0.0358 & 0.0105 & 0.0036 & 0.0023 & 0.0012 & 0.006 & 0.0104 & 0.0022 & 0.0016 & 0.0016 \\
\hline
\end{tabular}


TABle 4: Continued.

\begin{tabular}{lccccccccccc}
\hline & & BPO-S & BPO-V & BGA & BGWO & BBA & BHHO & BASO & BDE & BPSO & BTGA \\
\hline \multirow{4}{*}{ nci9 } & Best & 1.3296 & 1.3267 & 1.1735 & 1.1629 & 1.1726 & 1.2093 & 1.3127 & 1.0949 & 1.1728 & 1.1663 \\
& Avg & 1.0929 & 1.1854 & 1.0703 & 1.0431 & 1.0681 & 1.0809 & 1.217 & 0.9878 & 1.0679 & 1.053 \\
& Worst & 0.9786 & 1.0738 & 1.0061 & 0.975 & 1.0022 & 0.993 & 1.1225 & 0.9168 & 1.0025 & 1.0006 \\
& std & 0.0729 & 0.0509 & 0.043 & 0.0401 & 0.0403 & 0.0428 & 0.0393 & 0.0375 & 0.0394 & 0.0422 \\
\hline \multirow{4}{*}{ Prostate_GE } & Best & 1.4972 & 1.4999 & 1.2674 & 1.2583 & 1.2614 & 1.3822 & 1.4828 & 1.2572 & 1.2649 & 1.2622 \\
& Avg & 1.4272 & 1.4751 & 1.2625 & 1.2458 & 1.2583 & 1.3452 & 1.4644 & 1.2413 & 1.2609 & 1.2584 \\
& Worst & 1.2551 & 1.4378 & 1.258 & 1.2182 & 1.2557 & 1.3098 & 1.446 & 1.2059 & 1.2575 & 1.255 \\
& std & 0.0452 & 0.0204 & 0.0019 & 0.0114 & 0.0014 & 0.0151 & 0.0089 & 0.0135 & 0.0015 & 0.0016 \\
\hline \multirow{4}{*}{ SMK_CAN_187 } & Best & 1.3883 & 1.3916 & 1.1738 & 1.1665 & 1.1959 & 1.261 & 1.3986 & 1.1425 & 1.1969 & 1.1976 \\
& Avg & 1.2885 & 1.3294 & 1.1351 & 1.107 & 1.134 & 1.1691 & 1.3057 & 1.0722 & 1.1278 & 1.1305 \\
& Worst & 1.1754 & 1.276 & 1.1118 & 1.0616 & 1.089 & 0.0261 & 1.2642 & 1.0299 & 1.089 & 1.0889 \\
& std & 0.043 & 0.0231 & 0.017 & 0.0226 & 0.0203 & 0.0261 & 0.0261 & 0.0225 & 0.0197 & 0.024 \\
\hline
\end{tabular}

TABLE 5: Pairwise statistical comparison of the BPO-S algorithm with other algorithms using the Wilcoxon signed-rank test $(\alpha=0.05)$.

\begin{tabular}{|c|c|c|c|c|c|c|c|c|c|c|c|}
\hline Dataset & & BPO-S & BPO-V & BGA & BGWO & BBA & BHHA & BASO & $\mathrm{BDE}$ & BPSO & BTGA \\
\hline \multirow{2}{*}{ CLL_SUB_111 } & $p$-value & - & $1.786 E-04$ & $1.827 E-04$ & $1.827 E-04$ & $1.786 E-04$ & $1.827 E-04$ & $1.827 E-04$ & $1.827 E-04$ & $1.827 E-04$ & $1.827 E-04$ \\
\hline & Winner & - & - & + & + & + & + & - & + & + & + \\
\hline \multirow{2}{*}{ Colon } & $p-v$ & - & $1.575 E-04$ & $1.766 E-04$ & $1.766 E-04$ & $1.746 E-04$ & $1.776 E-04$ & $1.776 E-04$ & $1.766 E-04$ & $1.776 E-04$ & $1.756 E-04$ \\
\hline & & - & - & + & + & + & + & - & + & + & + \\
\hline \multirow{2}{*}{ Leukemia } & & - & $1.817 E-04$ & $1.817 E-04$ & $1.817 E-04$ & $1.806 E-04$ & $1.827 E-04$ & $1.827 E-04$ & $1.817 E-04$ & $1.806 E-04$ & $1.817 E-04$ \\
\hline & & - & - & + & + & + & + & + & + & + & + \\
\hline \multirow{2}{*}{ Lung } & & - & $1.827 E-04$ & $1.827 E-04$ & $1.827 E-04$ & $1.827 E-04$ & $1.827 E-04$ & $1.827 E-04$ & $1.817 E-04$ & $1.796 E-04$ & $1.817 E-04$ \\
\hline & & - & - & + & + & + & + & - & + & + & + \\
\hline \multirow{2}{*}{ Lung_discrete } & $p-\mathrm{v}$ & - & $1.817 E-04$ & $1.806 E-04$ & $1.817 E-04$ & $1.766 E-04$ & $1.817 E-04$ & $1.776 E-04$ & $1.786 E-04$ & $1.806 E-04$ & $1.806 E-04$ \\
\hline & Winner & - & - & + & + & + & + & - & + & + & + \\
\hline \multirow{2}{*}{ Lymphoma } & $p$-value & - & $1.827 E-04$ & $1.817 E-04$ & $1.817 E-04$ & $1.817 E-04$ & $1.817 E-04$ & $1.000 E+00$ & $1.817 E-04$ & $1.817 E-04$ & $1.796 E-04$ \\
\hline & Winner & - & - & + & + & + & + & $=$ & + & + & + \\
\hline \multirow{2}{*}{ nci9 } & $p$-value & - & $3.600 E-03$ & $1.405 E-04$ & $2.730 E-04$ & $3.447 E-04$ & $1.817 E-04$ & $1.932 E-03$ & $1.706 E-03$ & $8.501 E-04$ & $5.708 E-04$ \\
\hline & Winner & - & - & + & + & + & + & + & + & + & + \\
\hline \multirow{2}{*}{ Prostate_GE } & $p$-value & - & $4.600 E-03$ & $1.806 E-04$ & $1.806 E-04$ & $1.817 E-04$ & $7.650 E-04$ & $1.004 E-03$ & $1.817 E-04$ & $1.806 E-04$ & $1.806 E-04$ \\
\hline & Winner & - & - & + & + & + & + & + & + & + & + \\
\hline \multirow{2}{*}{ SMK_CAN_187 } & $p$-value & - & $2.100 E-02$ & $1.827 E-04$ & $1.827 E-04$ & $1.827 E-04$ & $1.827 E-04$ & $9.097 E-01$ & $1.827 E-04$ & $1.827 E-04$ & $1.817 E-04$ \\
\hline & Winner & - & - & + & + & + & + & $=$ & + & + & + \\
\hline
\end{tabular}

TABLE 6: Pairwise statistical comparison of the BPO-V algorithm with other algorithms using the Wilcoxon signed-rank test $(\alpha=0.05)$.

\begin{tabular}{|c|c|c|c|c|c|c|c|c|c|c|c|}
\hline Data & & BPO-S & BPO-V & BGA & BGWO & BBA & BHHA & BASO & $\mathrm{BDE}$ & BPSO & BTGA \\
\hline CLL_SUB_111 & & + & $\begin{array}{l}- \\
-\end{array}$ & $\begin{array}{c}786 E-04 \\
+\end{array}$ & $\begin{array}{c}786 E-04 \\
+\end{array}$ & $\begin{array}{c}1.786 E-04 \\
+\end{array}$ & $\begin{array}{c}1.786 E-04 \\
+\end{array}$ & $\begin{array}{c}5.354 E-02 \\
=\end{array}$ & $\begin{array}{c}786 E-04 \\
+\end{array}$ & $\begin{array}{c}1.786 E-04 \\
+\end{array}$ & $\begin{array}{c}.786 E-0 \\
+\end{array}$ \\
\hline Colon & & + & - & $\begin{array}{c}1.612 E-04 \\
+\end{array}$ & $\begin{array}{c}.612 E-04 \\
+ \\
\end{array}$ & $\begin{array}{c}1.593 E-04 \\
+\end{array}$ & $\begin{array}{c}1.621 E-04 \\
+\end{array}$ & $\begin{array}{c}3.954 E-04 \\
+ \\
\end{array}$ & $\begin{array}{c}612 E-04 \\
+\end{array}$ & $\begin{array}{c}1.621 E-04 \\
+\end{array}$ & $\begin{array}{c}1.602 E-0 \\
+\end{array}$ \\
\hline Leukemia & & + & - & $\begin{array}{c}1.806 E-04 \\
+\end{array}$ & $\begin{array}{c}1.806 E-04 \\
+\end{array}$ & $\begin{array}{c}1.796 E-04 \\
+ \\
\end{array}$ & $\begin{array}{c}1.817 E-04 \\
+\end{array}$ & $\begin{array}{c}2.821 E-04 \\
+\end{array}$ & + & + & $\begin{array}{c}1.806 E- \\
+ \\
\end{array}$ \\
\hline Lung & & + & - & $\begin{array}{c}1.827 E-04 \\
+\end{array}$ & $\begin{array}{c}1.827 E-04 \\
+\end{array}$ & $\begin{array}{c}1.827 E-04 \\
+\end{array}$ & $\begin{array}{c}1.827 E-04 \\
+ \\
\end{array}$ & $\begin{array}{c}4.274 E-01 \\
=\end{array}$ & $\begin{array}{c}1.817 E-04 \\
+ \\
\end{array}$ & $\begin{array}{c}1.796 E-04 \\
+ \\
\end{array}$ & $\begin{array}{c}1.817 E-0 \\
+\end{array}$ \\
\hline Lung_discrete & & $\begin{array}{r}1.817 E \\
+\end{array}$ & $\begin{array}{l}- \\
-\end{array}$ & $\begin{array}{c}796 E-04 \\
+\quad\end{array}$ & $\begin{array}{c}1.806 E-04 \\
+\end{array}$ & $\begin{array}{c}1.756 E-04 \\
+\end{array}$ & $\begin{array}{c}1.806 E-04 \\
+\end{array}$ & $\begin{array}{c}1.238 E-02 \\
=\end{array}$ & $\begin{array}{c}1.776 E-04 \\
+\end{array}$ & $\begin{array}{c}1.796 E-04 \\
+\end{array}$ & $\begin{array}{c}1.796 E-( \\
+\end{array}$ \\
\hline Lymphoma & & + & - & $\begin{array}{c}1.817 E-04 \\
+\end{array}$ & $\begin{array}{c}1.817 E-04 \\
+\end{array}$ & $\begin{array}{c}1.817 E-04 \\
+\end{array}$ & $\begin{array}{c}1.817 E-04 \\
+\end{array}$ & $\begin{array}{c}1.133 E-02 \\
=\end{array}$ & $\begin{array}{c}1.817 E-04 \\
+\end{array}$ & $\begin{array}{c}1.817 E-04 \\
+\end{array}$ & $\begin{array}{c}1.796 E-04 \\
+\end{array}$ \\
\hline nci9 & & $\begin{array}{c}3.600 E-03 \\
+\end{array}$ & $\begin{array}{l}- \\
-\end{array}$ & $\begin{array}{c}1.827 E-04 \\
+\end{array}$ & $\begin{array}{c}3.298 E-04 \\
+\quad\end{array}$ & $\begin{array}{c}5.828 E-04 \\
+\end{array}$ & $\begin{array}{c}1.827 E-04 \\
+\end{array}$ & $\begin{array}{c}1.827 E-04 \\
+\end{array}$ & $\begin{array}{c}1.827 E-04 \\
+\end{array}$ & $\begin{array}{c}1.827 E-04 \\
+\end{array}$ & $\begin{array}{c}5.828 E-04 \\
+ \\
\end{array}$ \\
\hline Prostate_GE & & $\begin{array}{c}4.600 E-03 \\
+\end{array}$ & - & $\begin{array}{c}1.817 E-04 \\
+\end{array}$ & $\begin{array}{c}1.817 E-04 \\
+\end{array}$ & $\begin{array}{c}1.827 E-04 \\
+\end{array}$ & $\begin{array}{c}1.827 E-04 \\
+ \\
\end{array}$ & $\begin{array}{c}7.337 E-01 \\
=\end{array}$ & $\begin{array}{c}1.827 E-04 \\
+\end{array}$ & $\begin{array}{c}1.817 E-04 \\
+\end{array}$ & $\begin{array}{c}1.817 E-0 \\
+\end{array}$ \\
\hline SMK_CAN_187 & & $\begin{array}{c}2.100 E-02 \\
+\end{array}$ & - & $\begin{array}{c}1.806 E-04 \\
+\end{array}$ & $\begin{array}{c}1.806 E-04 \\
+\end{array}$ & $\begin{array}{c}1.806 E-04 \\
+\end{array}$ & $\begin{array}{c}1.806 E-04 \\
+\end{array}$ & $\begin{array}{c}3.108 E-02 \\
+\end{array}$ & $\begin{array}{c}1.806 E-04 \\
+\end{array}$ & $\begin{array}{c}1.806 E-04 \\
+\end{array}$ & $\begin{array}{c}1.796 E-0 \\
+\end{array}$ \\
\hline
\end{tabular}


TABLE 7: The average number of selected features of the proposed algorithms compared to eight metaheuristics.

\begin{tabular}{lcccccccccc}
\hline Dataset & BPO-S & BPO-V & BGA & BGWO & BBA & BHHO & BASO & BDE & BPSO & BTGA \\
\hline CLL_SUB_111 & 257.3 & 187.62 & 5585.41 & 6384.14 & 5623.11 & 4399.46 & 1103.75 & 6901.91 & 5630.84 & 5662.63 \\
Colon & 42.34 & 31.03 & 907.2 & 979.4 & 944.51 & 626.94 & 125.54 & 1032.07 & 924.18 & 946.87 \\
Leukemia & 209.45 & 42.16 & 3240.73 & 3470.59 & 3404.03 & 1961.36 & 339.51 & 3498.41 & 3356.92 & 3400.45 \\
Lung & 83.61 & 109.25 & 1463.4 & 1615.38 & 1569.27 & 915.67 & 192.23 & 1629.41 & 1533.21 & 1566.4 \\
Lung_discrete & 45.69 & 31.56 & 121.74 & 149.94 & 138.7 & 94.9 & 25.31 & 158.4 & 129.2 & 137.73 \\
Lymphoma & 152.41 & 71.52 & 1574.2 & 1931.39 & 1903.45 & 1022.39 & 155.81 & 1959.52 & 1844.89 & 1890.76 \\
nci9 & 1627.87 & 785.56 & 4720.81 & 5232.5 & 4811.22 & 3932.79 & 1062.24 & 6128.74 & 4799.88 & 4879.49 \\
Prostate_GE & 170.27 & 171.27 & 2833.86 & 3032.71 & 2883.41 & 1841.66 & 424.93 & 3086.76 & 2853.46 & 2883.27 \\
SMK_CAN_187 & 222.56 & 371.68 & 9922.05 & 11069.31 & 9945.36 & 7199.64 & 1945.67 & 11519.65 & 9945.69 & 9977.48 \\
\hline
\end{tabular}

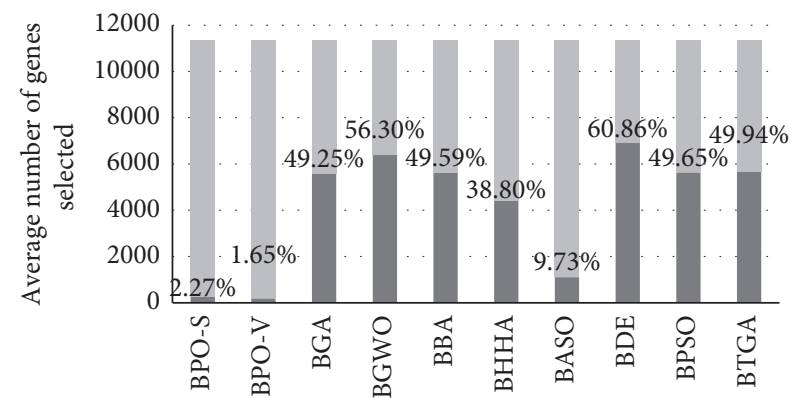

(a)

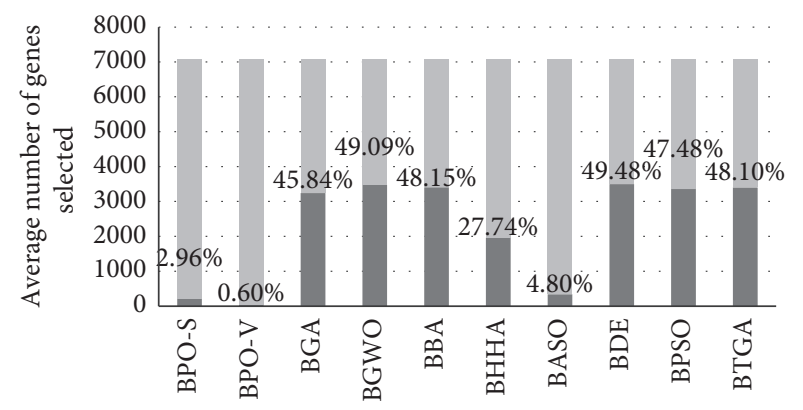

(c)

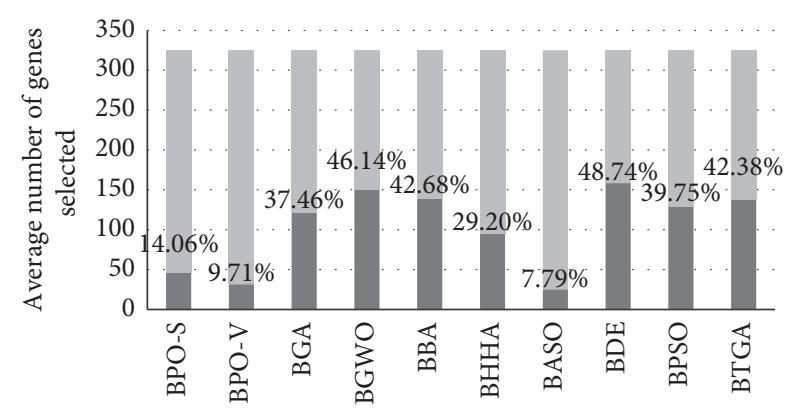

(e)

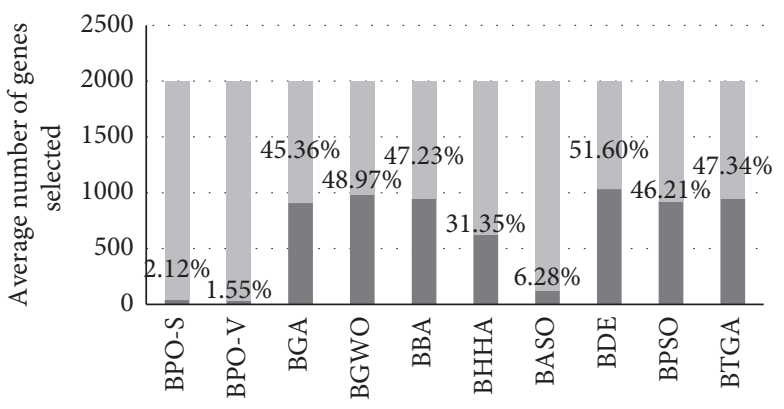

(b)

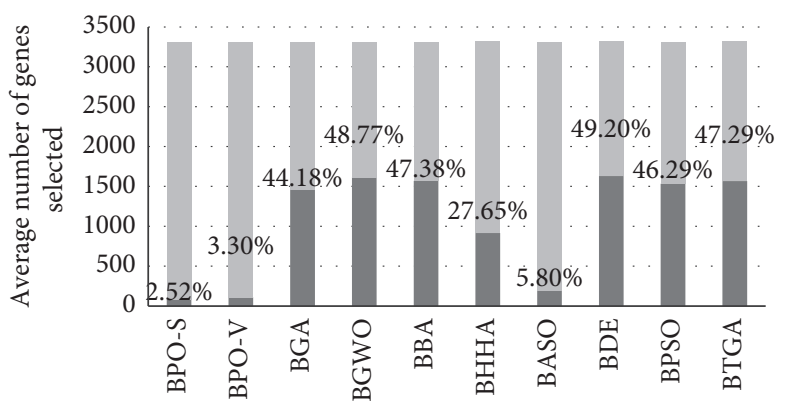

(d)

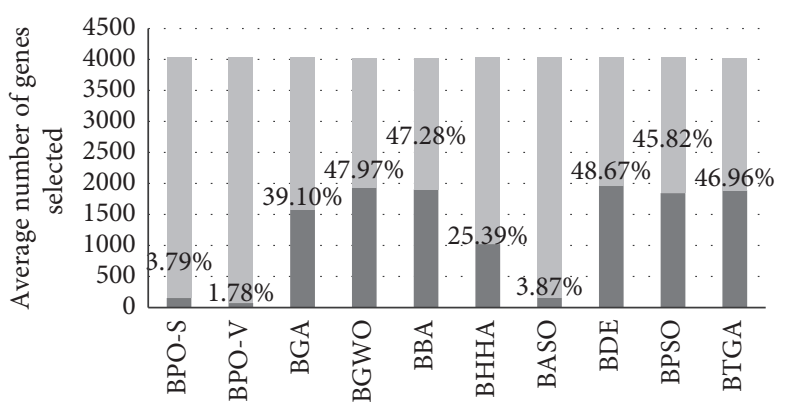

(f)

FIgURE 4: Continued. 


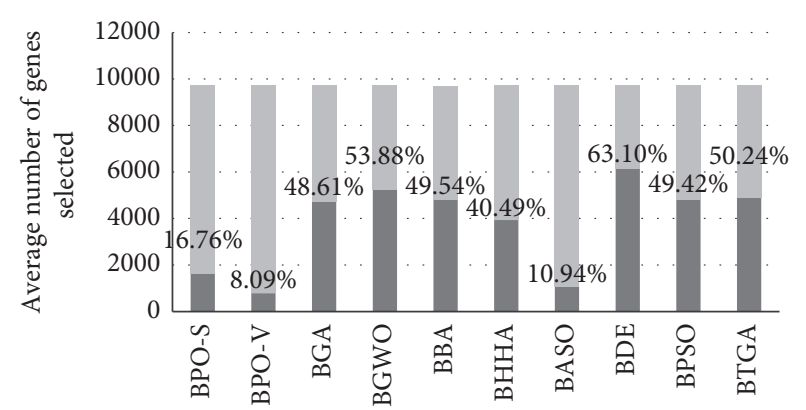

(g)

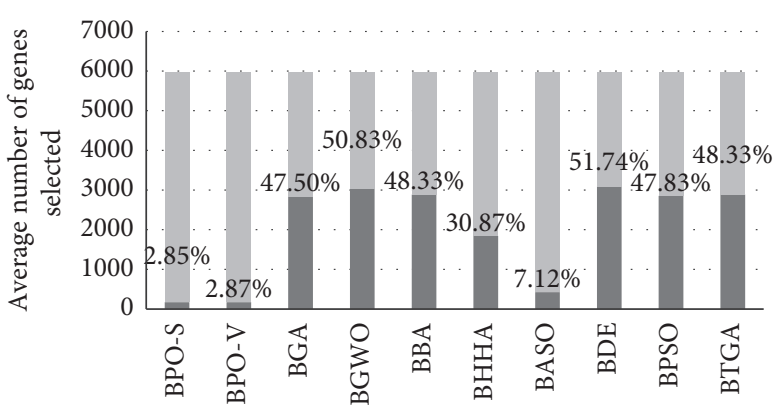

(h)

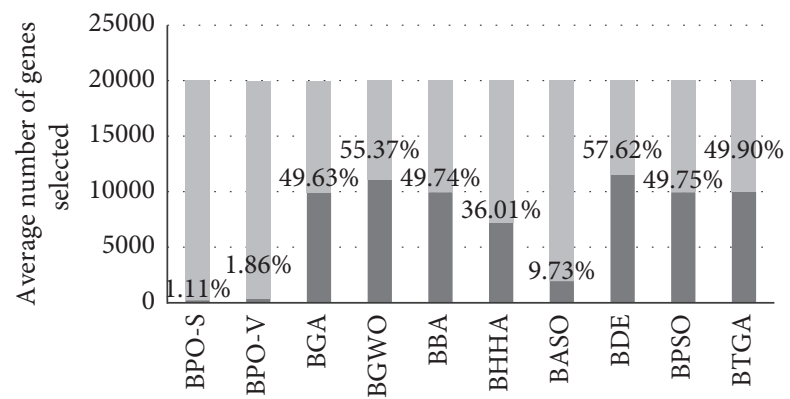

(i)

Figure 4: Average number of genes (features) selected for each of the 9 datasets (numbers on the bars indicate the percentage of selected genes).

TABLE 8: The average accuracy of the proposed algorithms compared to eight metaheuristics.

\begin{tabular}{|c|c|c|c|c|c|c|c|c|c|c|}
\hline Dataset/time (s) & BPOV1 & BPOV2 & BGA & BGWO & $\mathrm{BBA}$ & $\mathrm{BHHO}$ & BASO & $\mathrm{BDE}$ & BPSO & BTGA \\
\hline CLL_SUB_111 & 0.6864 & 0.6909 & 0.6818 & 0.5909 & 0.4545 & 0.5455 & 0.5000 & 0.6818 & 0.5000 & 0.5909 \\
\hline Colon & 0.8667 & 0.8500 & 0.8333 & 0.8333 & 0.7500 & 0.7500 & 0.8167 & 0.7500 & 0.7500 & 0.7500 \\
\hline Leukemia & 0.7714 & 0.9286 & 0.9286 & 0.8571 & 0.8571 & 0.8571 & 0.7143 & 0.7857 & 0.8571 & 0.9286 \\
\hline Lung & 0.9200 & 0.9250 & 0.9150 & 0.9150 & 0.9150 & 0.9000 & 0.8750 & 0.9250 & 0.9150 & 0.9200 \\
\hline lung_discrete & 0.8214 & 0.8571 & 0.7857 & 0.7857 & 0.8571 & 0.7143 & 0.6429 & 0.8571 & 0.7857 & 0.7143 \\
\hline Lymphoma & 0.8263 & 0.8947 & 0.8947 & 0.7895 & 0.8421 & 0.8947 & 0.7895 & 0.8421 & 0.8947 & 0.8947 \\
\hline nci9 & 0.4417 & 0.5167 & 0.3333 & 0.3333 & 0.5000 & 0.5000 & 0.2500 & 0.5000 & 0.4167 & 0.5000 \\
\hline Prostate_GE & 0.8650 & 0.9500 & 0.9000 & 0.9500 & 0.8500 & 0.9000 & 0.8500 & 0.7500 & 0.9500 & 0.9000 \\
\hline SMK_CĀN_187 & 0.8949 & 0.8516 & 0.6216 & 0.8108 & 0.8649 & 0.7297 & 0.7027 & 0.5946 & 0.6757 & 0.7568 \\
\hline
\end{tabular}
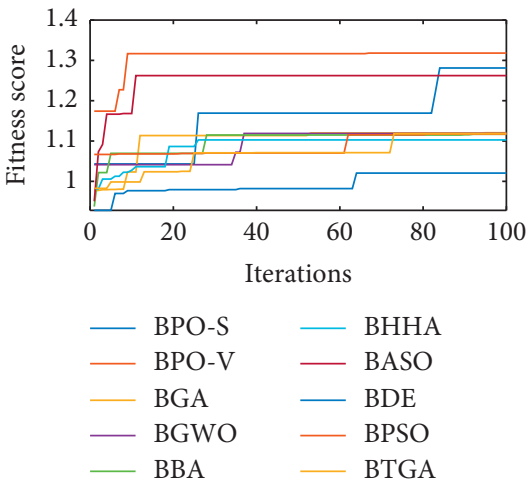

(a)
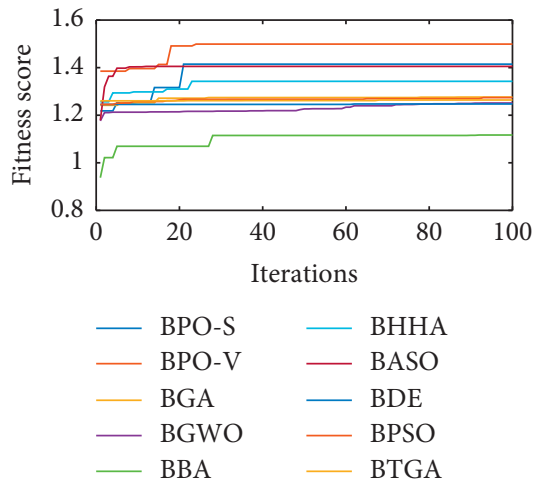

(b)

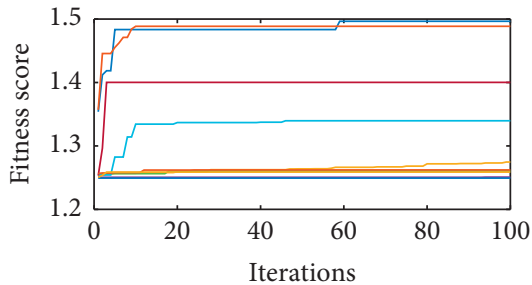

$\begin{array}{ll}- \text { BPO-S } & - \text { BHHA } \\ - \text { BPO-V } & \text { BASO } \\ - \text { BGA } & - \text { BDE } \\ \text { BGWO } & - \text { BPSO } \\ \text { BBA } & - \text { BTGA }\end{array}$

(c)

Figure 5: Continued. 


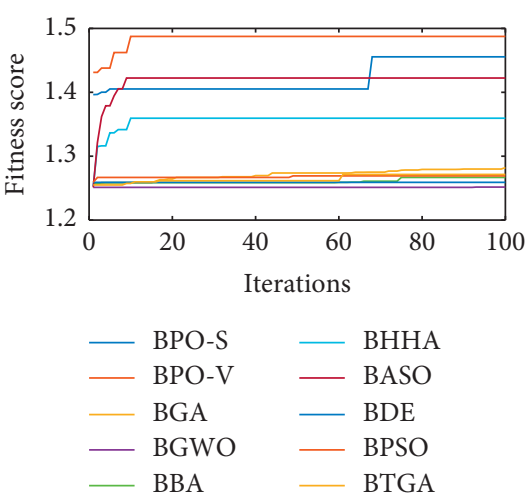

(d)
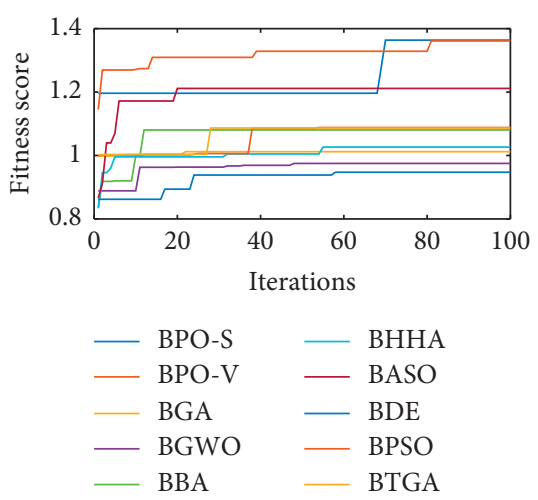

(g)

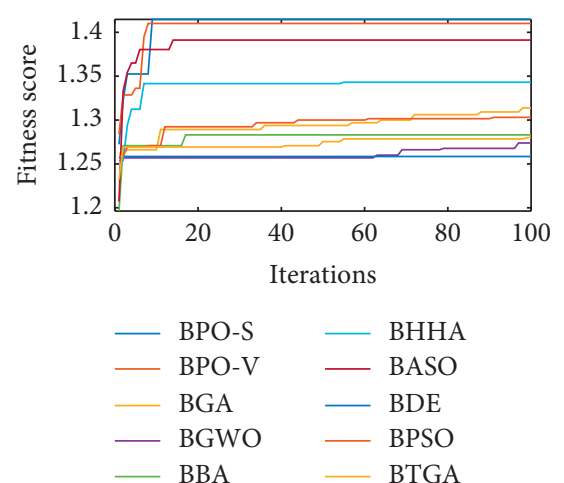

(e)
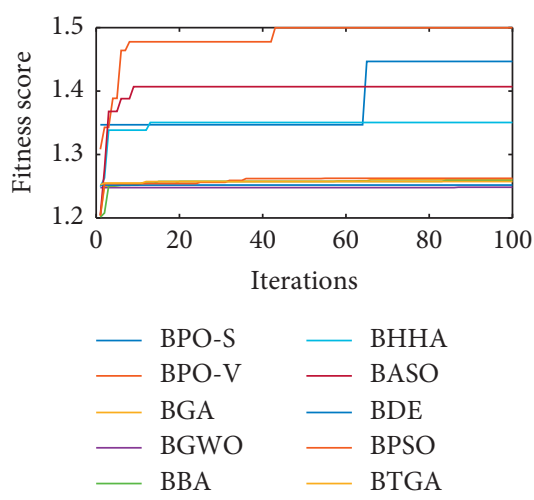

(h)
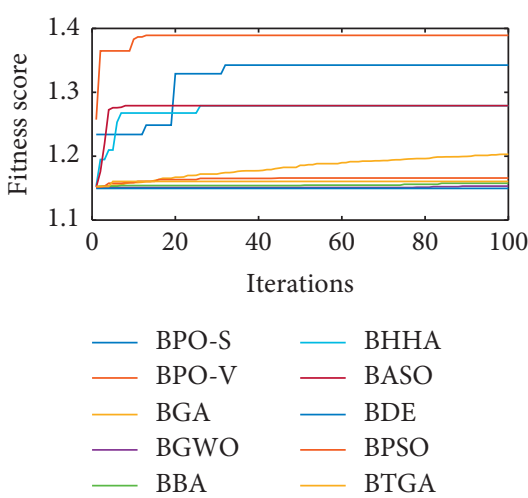

(f)
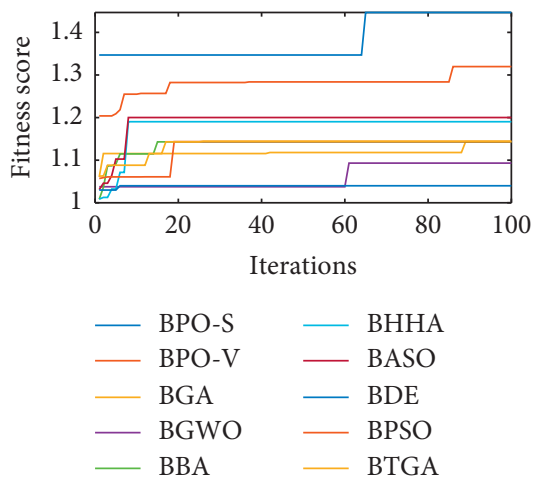

(i)

Figure 5: Convergence curves of the proposed approaches compared to 8 metaheuristics for each of the 9 datasets.

TABLE 9: The average execution time of the proposed algorithms compared to eight metaheuristics.

\begin{tabular}{lcccccccccc}
\hline Dataset/time (s) & BPO-S & BPO-V & BGA & BGWO & BBA & BHHO & BASO & BDE & BPSO & BTGA \\
\hline CLL_SUB_111 & 211.5163 & 166.0972 & 156.3265 & 156.1411 & 166.7361 & 269.3532 & 245.7208 & 172.91 & 235.5515 & 160.3811 \\
Colon & 103.2834 & 110.327 & 94.1061 & 96.418 & 94.6258 & 164.3746 & 105.777 & 89.9312 & 123.4293 & 93.9638 \\
Leukemia & 140.8718 & 117.0147 & 113.6496 & 127.0532 & 127.4182 & 195.2044 & 170.5102 & 115.6307 & 137.6324 & 110.3661 \\
Lung & 168.1855 & 135.1064 & 130.194 & 132.89 & 125.6319 & 227.7096 & 157.0562 & 139.6336 & 126.6119 & 116.7391 \\
lung_discrete & 111.4208 & 108.97 & 94.692 & 90.6665 & 82.4157 & 178.5376 & 101.8686 & 93.4482 & 80.0484 & 78.4514 \\
Lymphoma & 139.1397 & 117.5715 & 135.3171 & 109.7464 & 114.0983 & 202.2584 & 147.4745 & 116.1915 & 103.0365 & 100.1243 \\
nci9 & 163.066 & 127.4642 & 141.5162 & 138.7996 & 137.8389 & 226.385 & 236.8451 & 130.9642 & 128.7595 & 116.3961 \\
Prostate_GE & 161.4066 & 131.6549 & 125.0905 & 130.5117 & 130.1564 & 211.7674 & 188.3833 & 134.1632 & 119.473 & 114.9097 \\
SMK_CAN_187 & 519.7175 & 351.3269 & 253.5977 & 342.1177 & 332.1609 & 564.8705 & 423.7244 & 368.1337 & 342.0833 & 289.6829 \\
\hline
\end{tabular}

algorithms (BPO-S or BPO-V) statistically outperform in pairs the other ones with $95 \%$ significance level $(\alpha=0.05)$. In case of inferiority, the sign "-_" is used. From these tables, we can reaffirm in first place the superiority of BPO-S and BPO$\mathrm{V}$. Moreover, as mentioned before, the BASO algorithm is the most concurrent algorithm.

In the second step, to confirm this superiority, BPO-S and $\mathrm{BPO}-\mathrm{V}$ are evaluated in terms of accuracy and average number of selected features. From Table 7, it can be concluded that BPO-S and BPO-V outperform in an inescapable way the other algorithms regarding the number of selected features. Hence, Figure 4 is drawn to better visualize the obtained results. One more time, BASO showed the most competitive behavior. On the contrary, Table 8 outlines the comparative results in term of accuracy, where it can be seen that $\mathrm{BPO}-\mathrm{V}$ is the best algorithm. Therefore, the proposed algorithms strongly reduce the number of selected features without losing important information to deal with the problem treated by the dataset.

At the end of this evaluation, we compare BPO-V and $\mathrm{BPO}-\mathrm{S}$ in terms of execution time and convergence. Regarding convergence speed and best fitness score obtained, Figure 5 shows that BPO-V also excels in this point. Generally, after 20 iterations, it reaches its optimum solution. On the contrary, despite the good results of BPO-S in terms of fitness score, this algorithm arrives at its best performance late, generally after 50 iterations. In the second term and which concerns the execution time, $\mathrm{BPO}-\mathrm{V}$ and $\mathrm{BPO}-\mathrm{S}$ showed poor results according 
to Table 9. This fact can be explained by the complexity of the algorithm proposed in [31] and its large number of functions to execute and large number of conditions to verify.

\section{Conclusions}

In this paper, we proposed two versions of binary $\mathrm{PO}$ algorithm and applied to feature selection problem on gene expression data. To assess the robustness of our work, we used 9 standard datasets characterized by their huge dimensionality. Obtained results are compared to 8 binary versions of well-known metaheuristics. Experimental results prove the excellence performance of proposed algorithm. The results are evaluated using different indicators assessing convergence, reduction size, accuracy, performance (fitness score), and runtime. In future work, BPO could be hybridized with other metaheuristic algorithms as well as another classifier instead of KNN such as SVM.

\section{Data Availability}

The data used to support the findings of the study are available at http://featureselection.asu.edu/datasets.php.

\section{Conflicts of Interest}

The authors declare that they have no conflicts of interest.

\section{References}

[1] A. Antoniadis, S. Lambert-Lacroix, and F. Leblanc, "Effective dimension reduction methods for tumor classification using gene expression data," Bioinformatics, vol. 19, no. 5, pp. 563-570, 2003.

[2] B. Cao, D. Shen, J. T. Sun, Q. Yang, and Z. Chen, "Feature selection in a kernel space," in Proceedings of the International Conference on Machine Learning (ICML), pp. 121-128, Corvallis, OR, USA, June 2007.

[3] E. Pashaei and N. Aydin, "Binary black hole algorithm for feature selection and classification on biological data," Applied Soft Computing, vol. 56, pp. 94-106, 2017.

[4] H. Liu and R. Setiono, "Chi2: feature selection and discretization of numeric attributes," in Proceedings of the 7th IEEE International Conference on Tools with Artificial Intelligence, Herndon, VA, USA, November 1995.

[5] J. R. Quinlan, "Induction of decision trees," Machine Learning, vol. 1, no. 1, pp. 81-106, 1986.

[6] J. Quinlan, C4. 5: Programs for Machine Learning, Morgan Kaufmann, Burlington, MA, USA, 1993.

[7] M. Robnik-Łikonja and I. Kononenko, "Theoretical and empirical analysis of relieff and rrelieff," Machine Learning, vol. 53, pp. 23-69, 2003.

[8] R. Kohavi and G. John, "Wrappers for feature subset selection," Artificial Intelligence, vol. 97, no. 1-2, pp. 273-324, 1997.

[9] I. Guyon and A. Elisseeff, "An introduction to variable and feature selection," Journal of Machine Learning Research, vol. 3, pp. 1157-1182, 2003.

[10] Y. Saeys, I. Inza, and P. Larranaga, "A review of feature selection techniques in bioinformatics," Bioinformatics, vol. 23, no. 19, pp. 2507-2517, 2007.
[11] U. Fayyad, G. Piatetsky-Shapiro, and P. Smyth, "From data mining to knowledge discovery in databases," AI Magazine, vol. 17, p. 37, 1996.

[12] B. Xue, M. Zhang, and W. N. Browne, "Particle swarm optimization for feature selection in classification: a multi-objective approach," IEEE Transactions on Cybernetics, vol. 43, no. 6, pp. 1656-1671, 2013.

[13] E. G. Talbi, Metaheuristics: from Design to Implementation, Vol. 74, John Wiley \& Sons, Hoboken, NJ, USA, 2009.

[14] R. Y. M. Nakamura, L. A. M. Pereira, K. A. Costa et al., "A binary bat algorithm for feature selection," in Proceedings of the 25th Conference on Graphics, Patterns and Images (SIBGRAPI), pp. 291-297, Ouro Preto, Brazil, August 2012.

[15] F. W. Glover and G. A. Kochenberger, Eds., Handbook of Metaheuristics, Springer Science \& Business Media, Vol. 57, Berlin, Germany, 2006.

[16] R. Meiri and J. Zahavi, "Using simulated annealing to optimize the feature selection problem in marketing applications," European Journal of Operational Research, vol. 171, no. 3, pp. 842-858, 2006.

[17] H. Zhang and G. Sun, "Feature selection using tabu search method," Pattern Recognition, vol. 35, no. 3, pp. 701-711, 2002.

[18] I. O. Oduntan, M. Toulouse, R. Baumgartner, C. Bowman, R. Somorjai, and T. G. Crainic, "A multilevel tabu search algorithm for the feature selection problem in biomedical data," Computers \& Mathematics with Applications, vol. 55, no. 5, pp. 1019-1033, 2008.

[19] W. Siedlecki and J. Sklansky, "A note on genetic algorithms for large-scale feature selection," Pattern Recognition Letters, vol. 10, no. 5, pp. 335-347, 1989.

[20] J. Bala, K. D. Jong, J. Huang, H. Vafaie, and H. Wechsler, "Using learning to facilitate the evolution of features for recognizing visual concepts," Evolutionary Computation, vol. 4, no. 3, pp. 297-311, 1996.

[21] L. Jourdan, C. Dhaenens, and E. Talbi, "A genetic algorithm for feature subset selection in data-mining for genetics," in Proceedings of the 4th Metaheuristics International Conference, MIC, pp. 29-34, Porto, Portugal, July 2001.

[22] L. S. Oliveira, R. Sabourin, F. Bortolozzi, and C. Y. Suen, “A methodology for feature selection using multiobjective genetic algorithms for handwritten digit string recognition," International Journal of Pattern Recognition and Artificial Intelligence, vol. 17, no. 6, pp. 903-929, 2003.

[23] R. Sharkawy, K. Ibrahim, M. M. A. Salama, and R. Bartnikas, "Particle swarm optimization feature selection for the classification of conducting particles in transformer oil," IEEE Transactions on Dielectrics and Electrical Insulation, vol. 18, no. 6, pp. 1897-1907, 2011.

[24] Y. Y. Wang, H. Zhang, C. H. Qiu, and S. R. Xia, "A novel feature selection method based on extreme learning machine and fractional-order Darwinian PSO," Computational Intelligence and Neuroscience, vol. 2018, Article ID 5078268, , 2018.

[25] M. H. Aghdam, N. Ghasem-Aghaee, and M. E. Basiri, "Text feature selection using ant colony optimization," Expert Systems with Applications, vol. 36, no. 3, pp. 6843-6853, 2009.

[26] Y. Chen, D. Miao, and R. Wang, "A rough set approach to feature selection based on ant colony optimization," Pattern Recognition Letters, vol. 31, no. 3, pp. 226-233, 2010.

[27] M. Schiezaro and H. Pedrini, "Data feature selection based on artificial bee colony algorithm," EURASIP Journal on Image and Video Processing, vol. 2013, no. 1, p. 47, 2013. 
[28] H. Rao, X. Shi, A. K. Rodrigue et al., "Feature selection based on artificial bee colony and gradient boosting decision tree," Applied Soft Computing, vol. 74, pp. 634-642, 2019.

[29] R. N. Khushaba, A. Al-Ani, and A. Al-Jumaily, "Feature subset selection using differential evolution and a statistical repair mechanism," Expert Systems with Applications, vol. 38, no. 9, pp. 11515-11526, 2011.

[30] E. Hancer, B. Xue, and M. Zhang, "Differential evolution for filter feature selection based on information theory and feature ranking," Knowledge-Based Systems, vol. 140, pp. 103-119, 2018.

[31] Q. Askari, I. Younas, and M. Saeed, "Political optimizer: a novel socio-inspired meta-heuristic for global optimization," Knowledge-Based Systems, vol. 195, Article ID 105709, 2020.

[32] S. Mirjalili and A. Lewis, "S-shaped versus v-shaped transfer functions for binary particle swarm optimization," Swarm and Evolutionary Computation, vol. 9, pp. 1-14, 2013.

[33] G. I. Sayed, A. Tharwat, and A. E. Hassanien, "Chaotic dragonfly algorithm: an improved metaheuristic algorithm for feature selection," Applied Intelligence, vol. 49, no. 1, pp. 188-205, 2019.

[34] C. Haslinger, N. Schweifer, S. Stilgenbauer et al., "Microarray gene expression profiling of b-cell chronic lymphocytic leukemia subgroups defined by genomic aberrations and $\mathrm{VH}$ mutation status," Journal of Clinical Oncology, vol. 22, no. 19, pp. 3937-3949, 2004.

[35] U. Alon, N. Barkai, D. A. Notterman et al., "Broad patterns of gene expression revealed by clustering analysis of tumor and normal colon tissues probed by oligonucleotide arrays," Proceedings of the National Academy of Sciences, vol. 96, no. 12, pp. 6745-6750, 1999.

[36] T. R. Golub, D. K. Slonim, P. Tamayo et al., "Molecular classification of cancer: class discovery and class prediction by gene expression monitoring," Science, vol. 286, no. 5439, pp. 531-537, 1999.

[37] A. Bhattacharjee, W. G. Richards, J. Staunton et al., "Classification of human lung carcinomas by mRNA expression profiling reveals distinct adenocarcinoma subclasses," Proceedings of the National Academy of Sciences, vol. 98, no. 24, pp. 13790-13795, 2001.

[38] H. Peng, F. Long, and C. Ding, "Feature selection based on mutual information: criteria of max-dependency, max-relevance, and min-redundancy," IEEE Transactions on Pattern Analysis and Machine Intelligence, vol. 27, no. 8, pp. 12261238, 2005.

[39] A. A. Alizadeh, M. B. Eisen, R. E. Davis et al., "Distinct types of diffuse large B-cell lymphoma identified by gene expression profiling," Nature, vol. 403, no. 6769, pp. 503-511, 2000.

[40] D. T. Ross, U. Scherf, M. B. Eisen et al., "Systematic variation in gene expression patterns in human cancer cell lines," Nature Genetics, vol. 24, no. 3, pp. 227-235, 2000.

[41] U. Scherf, D. T. Ross, M. Waltham et al., "A gene expression database for the molecular pharmacology of cancer," Nature Genetics, vol. 24, no. 3, pp. 236-244, 2000.

[42] D. Singh, P. G. Febbo, K. Ross et al., "Gene expression correlates of clinical prostate cancer behavior," Cancer Cell, vol. 1, no. 2, pp. 203-209, 2002.

[43] J. B. Welsh, L. M. Sapinoso, A. I. Su et al., "Analysis of gene expression identifies candidate markers and pharmacological targets in prostate cancer," Cancer Research, vol. 61, no. 16, pp. 5974-5978, 2001.

[44] A. Spira, J. E. Beane, V. Shah et al., "Airway epithelial gene expression in the diagnostic evaluation of smokers with suspect lung cancer," Nature Medicine, vol. 13, no. 3, pp. 361-366, 2007.

[45] L.-Y. Chuang, H.-W. Chang, C.-J. Tu, and C.-H. Yang, "Improved binary PSO for feature selection using gene expression data," Computational Biology and Chemistry, vol. 32, no. 1, pp. 29-38, 2008.

[46] O. H. Babatunde, L. Armstrong, J. Leng, and D. Diepeveen, “A Genetic Algorithm-Based Feature Selection," International Journal of Electronics Communication and Computers Engineering, vol. 5, pp. 899-905, 2014.

[47] S. Mirjalili, S. M. Mirjalili, and X.-S. Yang, "Binary bat algorithm," Neural Computing and Applications, vol. 25, no. 34, pp. 663-681, 2014.

[48] G. Pampara, A. P. Engelbrecht, and N. Franken, "Binary differential evolution," in Proceedings of the 2006 IEEE International Conference on Evolutionary Computation, pp. 1873-1879, IEEE, Vancouver, Canada, July 2006.

[49] E. Emary, H. M. Zawbaa, and A. E. Hassanien, "Binary grey wolf optimization approaches for feature selection," Neurocomputing, vol. 172, pp. 371-381, 2016.

[50] J. Too and A. Rahim Abdullah, "Binary atom search optimisation approaches for feature selection," Connection Science, vol. 32, pp. 1-25, 2020.

[51] T. Thaher, A. A. Heidari, M. Mafarja, J. S. Dong, and S. Mirjalili, "Binary Harris Hawks optimizer for high-dimensional, low sample size feature selection," in Evolutionary Machine Learning Techniques, pp. 251-272, Springer, Singapore, Asia, 2020.

[52] J. Too, A. Abdullah, N. Mohd Saad, and N. Mohd Ali, "Feature selection based on binary tree growth algorithm for the classification of myoelectric Signals," Machines, vol. 6, no. 4, p. 65,2018 . 